
e-ISSN 2016/Atual: 2525-7870 | e-ISSN 2015/2016: 2447-018X

\title{
O caso do Cabildo uruguaio e argentino: uma análise sobre os processos de patrimonialização frente as suas representatividades.
}

\author{
El caso del Cabildo de Uruguay y Argentina: un análisis de los procesos \\ de la herencia a través de su representatividad.
}

The case of the Cabildo Uruguayan and Argentine: an analysis of the heritage processes across their representativeness.

\author{
Juliana de Oliveira Plá ${ }^{1}$ \\ Dra. Ana María Sosa González ${ }^{2}$ \\ Dra. Rita Juliana Soares Poloni ${ }^{3}$ \\ Dr. Ronaldo Bernardino Colvero ${ }^{4}$
}

Resumo

$\mathrm{O}$ ato de preservar representa o lembrar de uma fase, marco ou ato do passado, o patrimônio assim, atua como testemunho de uma época. Ajuda no processo de identidade de um grupo, formula indicadores da construção social. É a ressignificação das manifestações culturais, tornando-as vivas, ganhando sentido para os indivíduos. $\mathrm{O}$ trabalho pretende frente à significação do patrimônio e a produção de discursos, analisar os processos de patrimonialização dos cabildos, presentes desde a época de instalação da localidade, de Montevidéu - Uruguai, e Buenos Aires - Argentina, demonstrando a diferença de posicionamento entre os dois países. Além disso, discorre sobre a influência do patrimônio nos processos de identidade e memória coletivas, que representam uma trajetória histórica e cultural.

Palavras-Chave: Argentina; discurso; patrimônio; significação, Uruguai.

\section{Resumen}

El acto de la preservación es recordarle de una etapa, lugar de interés o un acto del pasado, el patrimonio de este modo actúa como testigo de una época. Ayuda en el proceso de identidad de un grupo, formula indicadores de la construcción social. Es la reinterpretación de las manifestaciones culturales, por lo que a los vivos, ganando

\footnotetext{
1 Mestranda em Memória Social e Patrimônio Cultural - Universidade Federal de Pelotas - UFPel. Professora EBTT do Instituto Federal Rio-Grandense, Campus Avançado Jaguarão. juliana.pla@ gmail.com

2 Doutora em História; Centro Universitário La Salle Canoas, Rio Grande do Sul, Brasil. anasosagonzalez@gmail.com

${ }^{3}$ Doutora em Arqueologia; Universidade Federal de Pelotas - UFPel; Pelotas, Rio Grande do Sul, Brasil. julianapoloni@hotmail.com

4 Doutor em História; Universidade Federal de Pelotas - UFPel; Pelotas, Rio Grande do Sul, Brasil. rbcolvero@gmail.com
} 
significado para los individuos. El trabajo tiene la intención de transmitir la importancia del patrimonio y la producción de discursos, el análisis de los procesos de la herencia de los cabildos, presentes desde la época de instalación de la localidad de Montevideo - Uruguay, y Buenos Aires - Argentina, que muestra la diferencia entre los dos posicionamiento países. Además, se analiza la influencia de la equidad en los procesos de identidad y la memoria colectiva, lo que representa una trayectoria histórica y cultural.

Palabras claves: Argentina; discurso; patrimônio; significación; Uruguay

\begin{abstract}
The act of preserving reminds of a stage, landmark or act of the past, the heritage thus acts as a witness of an era. Helps in the identity process of a group, formulates indicators of social construction. It is the reinterpretation of cultural manifestations, making the living, getting meaning for individuals. The work intends to forward the heritage significance and the production of speeches, analyzing the heritage processes of the cabildos, existing since the begnning of the installation location of Montevideo - Uruguay, and Buenos Aires - Argentina, showing the difference between the two countries. In addition, it discusses the influence of the equity in the processes of identity and collective memory, representing a historical and cultural trajectory.
\end{abstract}

Keywords: Argentina; heritage; significance; speech; Uruguay.

\title{
1. Introdução
}

A memória de um passado comum carrega informações e experiências vividas, podendo ser individuais ou coletivas. Segundo Halbwachs (1990) a memória coletiva nasce de relatos que ultrapassam gerações, ocorre do casamento da memória individual com estes relatos, a partir do ponto que os indivíduos tomam para si memórias do grupo ao qual se tem contato. Com isso, pode-se dizer que estas memórias não tem uma forma nítida, uma vez que se trata de memórias de outras épocas. Para que isso seja renovado são necessários elementos que sirvam de testemunho de uma época, que possam traduzir de outras maneiras o passado.

É possível ainda crer que o reconhecimento destas memórias e a produção de outras vincula o sentimento de identidade. Izquierdo (2002) complementa nesse sentido quando define memória como o senso histórico e senso de identidade pessoal. É através das lembranças que acessamos as memórias, fortalecendo a identidade, algo formado e transformado de maneira inconsciente através do tempo, nunca e encerrada.(Stuart Hall, 2000).

Para Candau(2012) o patrimônio exerce influência sobre a memória, atua na formação da identidade coletiva e individual, formulam indicadores da construção social de identidades. Com isso, o ato de preservar está relacionado ao esquecer tanto quanto ao lembrar, ao se definir o que e como deve ser preservado define-se também o que deve ser esquecido. $\mathrm{Ou}$ seja, o patrimônio como testemunha de uma época, além de representar uma trajetória histórica cultural desenvolve os contornos de identidade de determinada comunidade, é a escolha do recorte que se quer guardar. É a ressignificação das manifestações culturais, 
tornando-a viva, ganhando sentido para os indivíduos. É um processo social, político e simbólico. (Halbwachs, 1976; Jelin, 2001)

Os monumentos, segundo Riegl (2014) impulsionam no espectador a sensação de ciclo da vida. O surgimento desta sensação independe do saber erudito ou da educação histórica. É baseada na relação de valor que se aplica a determinado elemento, que se tem relação com o discurso que o envolve. Percebe-se com isto a necessidade de explicitar e valorizar o enraizamento das comunidades, sendo imprescindível para a manutenção das relações históricas e sociais que se deseja preservar. Completando esse pensamento, Colvero (2015) aponta que a preservação de um patrimônio implica além do reconhecimento da importância deste perante a sociedade, a promoção da democratização e da cultura.

Frente a isto, a cidade/sociedade como organismo vivo, em constante desenvolvimento e mudanças de referenciais as políticas públicas de requalificação devem estar relacionadas com sua história e à sua vocação (ARGAN,1992). Atualmente entende-se o patrimônio não somente bens imateriais, mas também bens materiais, incorporando assim toda a diversidade que envolve a produção destes bens e a importância para as comunidades às quais pertencem (RODRIGUES, 2014).

Para Llorenç Pratts(2005) patrimônio é resultado de um complexo processo de patrimonialização. O autor sugere que esses processos partem de duas construções distintas e complementares: a primeira como um sistema de representação, onde a legitimação se dá a partir de referentes simbólicos - natureza, história ou genialidade; a segunda seria resultado de ações de sujeitos concretos que selecionam as representações e as elaboram frente a um discurso, seria a "puesta en valor o activación" (PRATS, 2005, p.19). Com isso pode-se concluir que o discurso patrimonial, social ou institucionalizado, é parte central do processo. Este pode instituir a aceitação ou não de determinado patrimônio.

Quando relacionado a fins político-ideológicos e/ou posicionamento nacionalistas, o patrimônio desempenha um papel de relação entre passado e presente, podendo presenciar um movimento patrimonial que além de sua recuperação busca por algo do passado que legitime ações do presente, como por exemplo, legitimação de heróis nacionais, monumentos ou até mesmo o apagamento de bens materiais que remetem determinado posicionamento.(COLVERO, 2015)

Ainda neste sentido, quando as ações patrimoniais são fruto do interesse público (comunidade ou sociedade) resultam em práticas de total pertencimento e identificação cultural. O patrimônio só existe no cenário das representações, são significados e valores que mudam com o tempo, com a sociedade e seus referenciais. Souza Filho (1999) ainda defende 
que a representação, evocação ou memória cadenciam o sentido de preservação. Riegel(2014) compreende que o processo de reconhecimento de determinado elemento é resultado de sua representatividade, sendo esta inerente ou não à sua criação. $O$ autor trabalha com os conceitos de monumentos intencionais e não-intencionais. E com isso define que os caminhos a serem tomados pelas políticas públicas devem compactuar com estes aspectos.

A instituição de um patrimônio, como relatado anteriormente, deriva de vários agentes. A compreensão de sua vocação e representatividade para a localidade onde ele está inserido atua como potencializadores ou não desses processos de patrimonialização. Discutese então se estes aspectos estão presentes nos processos de ativação e na percepção do coletivo.

Busca-se com este trabalho identificar as políticas públicas de preservação do patrimônio edificado; Identificar as divergências e semelhanças entre as políticas públicas dos dois países em questão (Argentina e Uruguai); apontar limitantes projetuais e de apropriação de edificações históricas; ao final compreender a trajetória de significação das edificações para a comunidade.

Para a realização do proposto acima, foram escolhidos como estudo de caso, as duas edificações do Cabildo sendo uma no Uruguai e outra da Argentina, ambos nas capitais. A escolha por estes dois exemplares deu-se pela diferença da preservação arquitetônica sofrida por estes. Enquanto o primeiro exemplar apresenta-se intacto o segundo sofreu diversas alterações ao longo do tempo. As políticas de públicas de preservação serão analisadas através da legislação vigente de cada país, Argentina e Uruguai. As análises serão feitas frente a aspectos históricos, fotografias disponíveis na internet, inventários de tombamento e legislações pertinentes.

\section{Cabildo uruguaio - Montevidéo}

A localidade, hoje compreendida como Ciudad Vieja, é datada de 1726 recebendo alguns desbravadores de Buenos Aires e das Ilhas Canárias. Logo foi construída a fortificação e de acordo com as Leis das Índias definidas as quadras e localização das principais edificações. Em $1^{\circ}$ de janeiro de 1730 a sede do Cabildo é instalada na residência do Capitão Pedro Gronardo, em uma estrutura vernacular de adobe e cobertura em couro. Quatro anos após, devido à instabilidade da edificação, as reuniões ocorreram em diversos locais de importância política para a sociedade da época e também na igreja matriz. Neste momento foi definido novo local para a construção da edificação e iniciam-se as obras de "una sala de 
nueve varas de hueco y de ancho cinco, con dos puertas y dos ventanas, con la altura que fuese necessária." (CASTELLANOS, 1971 p.39).

A construção arrastou-se por 13 anos, devido à escassez de materiais, e foi em 1750 que o Cabildo inicia seus trabalhos no mesmo local que se encontra hoje. Por mais 30 anos a edificação foi alvo de inúmeras reformas, como colocação de ladrilhos, ampliação de seu espaço para instalação de salas carcerárias e de usos administrativo, colocação de um frontão com as armas reais e as da cidade, entre outras. Em 1780 iniciam-se as obras de um segundo piso que deveriam acomodar a "Sala de acuerdos". As reformas estendem-se por mais alguns anos devido ao crescimento da população carcerária e outros problemas de origem estrutural. (CASTELLANOS, 1971)

Somente em 1804 que se iniciam as intervenções de maneira satisfatória, sob a coordenação do Arquiteto Tomás Toribio, utilizando-se de técnicas construtivas mais sólidas. Após sua morte, é substituído por seu filho José Toribio que em 1830 coordena as obras de reparações para a instalação da Câmara do Poder Legislativo, conservando o aspecto original do projeto. No período de 1867 a 1869 foram executados trabalhos na fachada, com a instalação de símbolos referentes ao seu uso, sendo mantida até os dias de hoje, em Estilo Neoclássico Espanhol. (Montevideo, 2010).

Definido como sede do Poder Legislativo Nacional até 1925 foi ocupado posteriormente pelo Conselho Nacional de Administração e pelo Ministério de Relações Exteriores. No período de 1957 a 1959 passou por reformas a fim de voltar ao estado original, sofrendo algumas alterações em seu interior. Em 1925 inaugura-se no prédio o Museu e Arquivo Histórico Nacional, utilizado para este fim até a data de hoje e somente em 1975 é declarado Monumento Nacional pela “Comisión Del Patrimônio Cultural De La Nación” criada pela Lei 14.040 de 1971.

Mariano Arana(2014) cita 1979, como o início do período das maiores perdas patrimoniais da história da cidade muralhada, a Ciudad Vieja. A perda da condição de monumentos históricos de centenas de edifícios pela ditadura militar resultou na troca de diversos exemplares de importância histórica e estética por edifícios descontextualizados com o entorno e de irrelevância compositiva, além do surgimento de vazios urbanos, inexistentes anteriormente no território urbano histórico. Em resposta a isto, um grupo de jovens arquitetos e estudantes iniciaram o chamado "Grupo de Estudios Urbanos", que com o apoio da "Sociedad de Arquitectos del Uruguay" e de personalidades reconhecidas na trajetória do país dão voz a processos de denúncias e ações de esclarecimento contra a destruição do patrimônio. 
Foi somente em 1982, que tal esforço rendeu algum resultado. Mesmo antes da instalação da democracia, foram canceladas as permissões de demolição ou de novas construções no centro histórico de Montevideo. Frente a necessidade de desenvolvimento urbano, pertinente a qualquer sociedade, cria-se a "Comisión Especial Permanente de la Ciudad Vieja", atuante até os dias de hoje, com a responsabilidade de desenvolver o inventário arquitetônico básico. Em 1998 o "Plan de Ordenamiento Territorial de Montevideo" foi aprovado, definindo assim algumas diretrizes para intervenções no contexto urbano histórico. (Arana, 2014).

No ano de 2015, foi lançado em Montevideo o "Programa Revitalización Ciudad Vieja", integrante do "Plan Especial de Ordenación, Protección y Mejora de Ciudad Vieja" (Decreto Departamental № 30.565), com a intenção de promover melhorias gerais da área deste centro histórico, compatibilização da preservação dos valores do espaço urbano existente com um desenvolvimento sustentável do mesmo, ordenação do espaço edificado e do espaço público, vazios urbanos e traçado urbano em geral. O programa envolve o entorno imediato do centro e apresenta quatro eixos principais para atuação, sendo eles: mobilidade sustentável; acessibilidade universal, espaço público como ponto de encontro e democratização; e gestão integrada.

Para tanto se iniciou o trabalho com o desenvolvimento do "Inventario Del Patrimonio Arquitectónico Y Urbanístico De La Ciudad Vieja"5. O inventário (com 2300 elementos catalogados) conta além da tabulação de cada elemento arquitetônico, praça ou vazio urbano com suas características físicas e diagnóstico, com um "Sistema de Información Urbano" para organizar e manusear de forma ágil todas as informações do inventário. Para os fins deste trabalho, serão analisados os termos gerais de inventário bem como a planilha de inventário do Cabildo. ${ }^{6}$

O "Inventario de Protección Patrimonial" é uma ferramenta de diagnóstico e análise do valor patrimonial acerca de uma determinada região ou construção. Como instrumento técnico administrativo, indica os caminhos para estabelecer uma política de preservação resultando em elaborações de propostas de proteção, intervenção e gestão do patrimônio. Neste inventário foram analisadas edificações, entornos urbanísticos e paisagens urbanas. Com isso, o inventário identifica diferentes padrões e os individualiza. Com o uso de uma

\footnotetext{
5 Inventario del patrimonio arquitectónico y urbanístico de La Ciudad Vieja. Disponível em: http://inventariociudadvieja.montevideo.gub.uy/ acessado em 20 de junho de 2016.

${ }_{6}^{6}$ Maiores detalhes consultar http://inventariociudadvieja.montevideo.gub.uy/padrones/4597 acessado em 20 de junho de 2016.
} 
ficha catalográfica, é possível analisar de forma direta cada elemento e obter um nível de informação similar a todos os padrões permitindo ainda a comparação entre eles.

Quando analisados os padrões, são avaliados alguns critérios como: tipologia, características definidoras da imagem de uma região, qualidade construtiva, representatividade em relação ao desenvolvimento da cultura arquitetônica local ou nacional, linguagem arquitetônica; tratamento de fachada entre outros. ${ }^{7}$

Ainda no inventário foram determinados graus de proteção patrimonial, que reconhece a importância testemunhal de determinado edifício. Este podende estar vinculado ao seu valor histórico e/ou cultural, morfológico, tipológico, elementos significativos, integração com o entorno e importância como elementos de referência urbana. Para tanto, foram estabelecidos uma graduação de cinco níveis sendo o "valor zero" menor importância e "valor quatro" de maior importância. Estes níveis de graduação ainda definem quais ações podem sofrer a edificação em favor de sua conservação.

Diante do exposto, analisa-se a planilha do inventário referente ao Cabildo de Montevideo. Esta apresenta em sua sessão de identificação, a localização e alguns aspectos históricos acerca do edifício. São anexadas algumas imagens de diversos períodos, inventários anteriores e imagens históricas, onde se pode perceber que a edificação encontra-se em alto estado de conservação. Aspectos como usos, tipologia arquitetônica, propriedade, responsável pelo projeto e etc estão vinculados na sessão de informações e ainda apresenta na sessão de características aspectos como morfologia, sistema construtivo, estado de conservação e etc. Contudo, é na continuação deste inventário que se encontram informações relevantes para este estudo.

O processo de inventário, como descrito acima define a edificação frente a questões físicas da arquitetura e sua trajetória no tempo, estado de conservação. Porém nas sessões de "Valoración", "Evaluación" e "Grado de protección" são apresentadas as características da edificação como elemento representativo na história da cidade. Definem-se laços memoriais com a história de expansão da cidade e sua importância no processo.

O prédio do Cabildo assim é definido como importante edifício do passado colonial e republicano, pertencente a um entorno significativo e representando uma imagem urbana relevante. Em avaliação urbana é definido como “(...)uno de los edifícios más emblemáticos de la Ciudad Vieja y de Montevideo em general”. Em questões arquitetônicas são destacadas os valores arquitetônicos e simbólicos, assim como valor estético e testemonial.

\footnotetext{
${ }^{7}$ Dados retirados do site oficial de Montevideo sobre o inventário, disponível em: http://inventariociudadvieja.montevideo.gub.uy/node/2302 acessado em 20 de junho de 2016.
} 


\section{Cabildo argentino - Buenos Aires}

A edificação do Cabildo em Buenos Aires, assim como em Montevidéo iniciou-se com técnicas construtivas simples, no mesmo local que se encontra hoje, em 1608, porém no ano de 1632 é abandonada pela precariedade de sua estrutura apesar de ter passado por reformas no ano de 1621 . Por ordens da Coroa, o arquiteto espanhol jesuíta padre Juan Bautista Prímoli é encarregado de projetar a nova sede do cabildo. No ano de 1725, outro arquiteto, também jesuíta, toma seu lugar remodelando o projeto original que ainda não havia sido finalizado. Somente vinte e seis anos depois a construção é concluída com exceção da torre que será finalizada em 1763 recebendo o primeiro relógio da cidade.

Após a Revolução de Mayo, em 1821 o Cabildo realiza seu ultimo acordo sendo dissolvido. Suas atribuições são, então, repartidas pelos três poderes que surgem com o nascimento da província. O final da Revolução é marcado pela ruptura de Buenos Aires com a Coroa Espanhola, e sendo assim ações de apagamento desta relação ocorrem. O Cabildo sofre mudanças no uso e em sua composição estética, recebendo em 1860 mais dez metros de altura em sua torre, cúpula azulejada com ares nórdicos. Perde suas tracionais telhas e os balcões, típicos da arquitetura espanhola, que são substituídos por balaustradas. O arco principal é emoldurado por colunatas e toda a fachada passa a receber um tratamento "italinizante".

Em 1880, o eleito presidente Julio Roca eleva a significação de Buenos Aires, sendo declarada capital da Argentina. O período é marcado por grande prosperidade, ocorre uma maciça imigração europeia, iniciam-se construções de ferrovias e alavancando as exportações agrícolas e com isso a economia. Com os chegados da Europa, Buenos Aires inspira-se nos moldes da França e inicia assim uma remodelação urbana (Lenz, 2010). O Cabildo agora torna-se sede dos Tribunais Nacionais e passa por remodelação em sua estrutura, sob a responsabilidade do arquiteto francês Pedro Benoit, e também em sua fachada. Recebe o terceiro nível em sua torre e ganha um estilo classicista franco-italiano.

Já em 1889, iniciam-se as obras de construção da Avenida de Mayo e com isso o prédio do cabildo perde três arcos e, consequentemente, a torre põe riscos à estrutura. Segundo Monica Rotman (2011), os anos dez do século XX é o momento chave no processo de preocupação com a construção da "argentinidade". Sob influência da comemoração do centenário da Revolução de Mayo, várias edificações assumem papel de monumentos nacionais como resposta pela preocupação com a identidade da pátria.

Vinte e um anos depois, com a abertura da via diagonal Julio A. Roca a edificação do Cabildo perde mais três arcos. Para evitar a demolição total a prefeitura reclama a posse da 
edificação ao poder executivo. Através de uma campanha nos meios de comunicação, a favor da defesa do patrimônio histórico e cultural, provoca a conscientização e mobilização da opinião pública que define o Cabildo como Monumento Nacional destinando-o ao Museu Histórico Nacional através da ley 11.688 de 1933.

Em 1938 a Comissão Nacional de Museus e de Monumentos e Lugares Históricos (CNMMLH) encomenda ao Arq. Mario Buschiazzo o projeto para a restauração da edificação. Através de documentos iconográficos, escrituras e projetos se reconstrói o edifício recuperando assim sua primeira forma estética, com referências típicas espanholas. A torre e o balcão são reconstruídos harmonizando com os cinco arcos remanescentes da base. A nova edificação é inaugurada em 12 de outubro de 1940.

Rotman ainda pontua que o processo iniciado em 1910, "consolidou a noção cultural essencialista da nação" (ROTMAN, 2011, p. 59). Porém todo o esforço desta ação não refletia a diversidade populacional e cultural, atingido apenas a elite. Frente a isso, ainda ocorreram uma série de ações em busca da formação e prática da nacionalidade. No âmbito do patrimônio foi surge o CNMMLH que declara de forma mais clara a tentativa de um discurso único e oficial. A história é convertida em questão de Estado.

Atualmente no âmbito cultural, Buenos Aires apresenta diversas ações para implementação de políticas e estratégias para a revitalização do Centro Histórico e desenvolvimento urbano desta área. Busca também o fortalecimento de sua identidade histórica e sócio cultural, através do desenvolvimento sustentável. Nas edificações já catalogadas, a gestão se direciona para a preservação daqueles edifícios que se mantiveram intactos apesar das substituições que ocorreram ao longo do tempo, sendo assim catalogados como edifícios singulares.

A esses edifícios são vinculados três níveis de proteção : Protección Integral, destinado aos exemplares com interesse especial, cujo valor histórico e/ ou arquitetônico os constituem como marcos urbanos; Protección Estructural, exemplares singulares que apresentam valor histórico frente ao entorno urbanístico; e por fim Protección Cautelar onde estariam contempladas as edificações que o valor reconhecido é artístico de uma referência formal e cultural.

Ainda são definidos frente a critérios de valoração, vinculados a valores históricos, culturais, estilísticos e testemunhais, sintetizados ainda em urbanísticos, arquitetônicos, histórico-cultural e singular. O Cabildo estaria vinculado então ao processo de valoração singular, sendo excluído assim da importância de elemento histórico-cultural.

\section{Considerações Finais}


Com o exposto, é possível perceber duas posturas distintas frente ao patrimônio edificado e ao discurso que o envolve. As políticas públicas de ativação em ambos os casos trabalham com o que se deseja representar.

Em relação ao processo de patrimonialização do Cabildo uruguaio, entende-se mais como um resultado obvio frente ao grau de preservação em que esta edificação se apresentava e apresenta. Talvez seja resultado de ter se mantido um uso constantemente coerente com o uso original, não necessitando assim de maiores alterações de sua estrutura. Resulta em um exemplar arquitetônico mais do que histórico, é um elemento da arquitetura colonial e de formação de uma província sob os modelos espanhóis.

O fato de tal edificação estar em um sítio histórico bem definido, dentro das muralhas mesmo que inexistente fisicamente, pode ter colaborado com sua permanência intacta. Não sendo alvo assim de alterações em seu significado tanto físico quanto simbólico. A história não se apresenta como conflituosa eliminando assim a necessidade de qualquer alteração física para sustentar um discurso.

Já no caso do Cabildo argentino o processo de patrimonialização é resultado de afirmação identitária. Em determinado momento histórico o exemplar perde sua função principal uma vez que essa ameaça o desenvolvimento político-social que se deseja instalar. Acaba por ser alvo de ações para instalação de discursos dos mais diversos que se apoiam na representatividade que um dia este exerceu sobre o desenho simbólico da cidade que ali se instalava. Foi alvo do desenvolvimento social, econômico e político.

Frente a isso questiona-se de que patrimônio estamos falando? Qual seria então o melhor posicionamento frente a estes casos? De um lado apresenta-se uma edificação que ficou inerte às mudanças sociais que ocorriam ao seu redor, sendo assim um exemplar de um momento específico e, de outro lado, uma edificação que foi mudando com o passar do tempo e com as mudanças de referenciais. Neste segundo, o que se mantém atualmente é um discurso de que a história não passou, não houve, assim. intervenções de distintas culturas que ainda se apresentam na estrutura social da cidade. Baseia-se no esquecimento de intervenções culturais de épocas passadas. Resulta-se assim um processo cíclico, onde preservar um fato é esquecer outro.

\section{Referências}

ARANA, Mariano. Luces y sombras de nuestro patrimônio arquitectónico. (texto para aula inaugural ministrada em 2014). 

e-ISSN 2016/Atual: 2525-7870 | e-ISSN 2015/2016: 2447-018X

ARGAN, G.C. A história da arte como história da cidade. São Paulo, Martins Fontes, 1992.

CASTELLANOS, Alfredo R. Montevidéo en el siglo XIX. Editorial Nuestra Tierra, 1971. Disponível em: http://www.periodicas.edu.uy/o/Nuestra_tierra/pdfs/3Montevideo_en_el_siglo_XIX.pdf acessado em: 4 de agosto de 2016.

COLVERO, Ronaldo. Severo, Marconi. A construção e a disputa pela hegemonia patrimonial em São Borja (RS): de primeiro dos Sete Povos Missioneiros à terra dos presidentes . Revista Confluências Culturais. v. 5, n. 1 - ISSN 2316-395X

HALBWACHS, Maurice. Les cadres sociaux de la mémoire. Paris: Mouton, 1976 A memória coletiva. Rio de Janeiro, Vertice, 1990.

IZQUIERDO, Ivan, Memórias. Estudos históricos. [on line]. 1989, vol.3, n.6, pp.89-112. http://dx.doi.org/10.1590/S0103-40141989000200006.

HALL, Stuart. A identidade cultural na pós-modernidade. Tradução: Tomaz Tadeu da Silva, Guaracira Lopes Louro. 4. ed. Rio de Janeiro: DP\&A. 2000. 102 p.

JELIN, Elizabeth. Los trabajos de la memoria. Siglo Veintiuno editores, España 2001.

LENZ, Maria Heloisa. A BUENOS AIRES DO FINAL DO SÉCULO XIX: A METRÓPOLE DA BELLE ÉPOQUE ARGENTINA. In.: Fênix - Revista de História e Estudos Culturais. Vol.9, ano IX, $\mathrm{n}^{\circ}$ 1. ISSN 1807-6971. Jan/Fev/Mar/Abr de 2012. Disponível em: WWW.revistafenix.pro.br Acesso em: 07 de agosto de 2016.

PRATS, Llorenç. Concepto y gestión del patrimonio local. Cuadernos de Antropología Social $\mathrm{N}^{\mathrm{o}} 21$, pp. 17-35, 2005.

RIEGL, Alois, 1858-1905. O culto moderno dos monumentos: a sua essência e a sua origem/ Alois Riegl; tradução Werner Rothschild Davidsohn, Anat Falbel. - I. ed. - São Paulo: Perspectiva, 2014.

RODRIGUES, Marcia Carvalho - Bibliotecas como lugares de memória: o caso sul-riograndense São Paulo, Unesp, v. 10, n.1 ,janeiro-junho, 2014.

ROTMAN, Mónica. A trama de uma instituição Estatal vinculada ao Patrimônio Argentino: contexto histórico e regulamentação. In: FERREIRA, Lucio M.; FERREIRA, Maria Letícia M., ROTMAN, Mónica (orgs) Patrimônio cultural no Brasil e na Argentina: estudos de caso. São Paulo, annablume, 2011.

SOUZA FILHO, Carlos Marés de. Bens culturais e proteção jurídica. 2. ed. rev. Porto Alegre: Secretaria Municipal da Cultura, Unidade Ed., 1999. p. 53. 